\title{
Decontamination \& Decommissioning Equipment Tracking System (DDETS)
}

\author{
RECEIVED \\ NOV 011994 \\ OSTI
}

July 1994

Idaho National Engineering Laboratory EG\&G Idaho, Inc.

P.O. Box 1625

Idaho Falls, ID 83415-3730

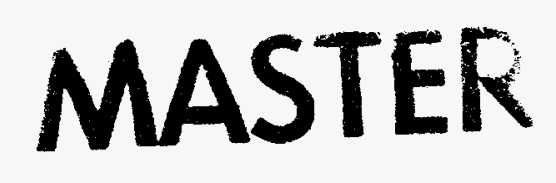


(THIS PAGE INTENTIONALLY LEFT BLANK) 


\section{ABSTRACT}

At the request of the Department of Energy (DOE)(EM-50), the Scientific Computing Unit developed a prototype system to track information and data relevant to equipment and tooling removed during decontamination and decommissioning activities. The DDETS proof-of-concept tracking system utilizes a one-dimensional (1D) and two-dimensional (2D) bar coding technology to retain and track information such as identification number, manufacturer, requisition information, and various contaminant information, etc. The information is encoded in a bar code, printed on a label and can be attached to corresponding equipment.

The DDETS was developed using a proven relational database management system which allows the addition, modification, printing, and deletion of data. In addition, communication interfaces with bar code printers and bar code readers were developed. Additional features of the system include:

- Four different reports available for the user (REAPS, transaction, and two inventory)

- $\quad$ Remote automated inventory tracking capabilities

- $\quad$ Remote automated inventory tracking capability (2D bar codes allow equipment to be scanned/tracked without being linked to the DDETS database)

- $\quad$ Edit, update, delete, and query capabilities

- $\quad$ On-line bar code label printing utility (data from 2D bar codes can be scanned directly into the data base simplifying data entry), and

- $\quad$ Automated data backup utility.

Compatibility with the Reportable Excess Automated Property System (REAPS) to upload data from DDETS is planned.

\section{DISCLAIMER}

This report was prepared as an account of work sponsored by an agency of the United States Government. Neither the United States Government nor any agency thereof, nor any of their employees, makes any warranty, express or implied, or assumes any legal liability or responsibility for the accuracy, completeness, or usefulness of any information, apparatus, product, or process disclosed, or represents that its use would not infringe privately owned rights. Reference herein to any specific commercial product, process, or service by trade name, trademark, manufacturer, or otherwise does not necessarily constitute or imply its endorsement, recommendation, or favoring by the United States Government or any agency thereof. The views and opinions of authors expressed herein do not necessarily state or reflect those of the United States Government or any agency thereof. 
(THIS PAGE INTENTIONALLY LEFT BLANK) 


\section{DISCLAIMER}

Portions of this document may be illegible in electronic image products. Images are produced from the best available original document. 


\section{CONTENTS}

\section{$\underline{\text { Page }}$}

ABSTRACT $\ldots \ldots \ldots \ldots \ldots \ldots \ldots \ldots \ldots \ldots \ldots \ldots \ldots \ldots \ldots \ldots$

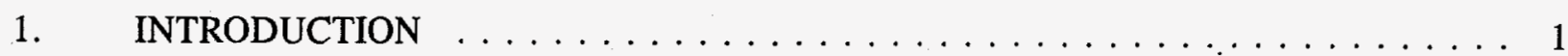

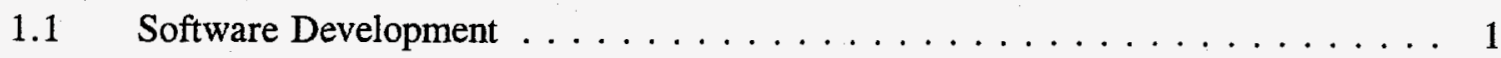

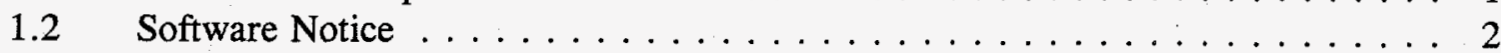

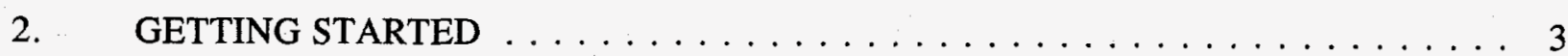

2.1 DDETS System Requirements $\ldots \ldots \ldots \ldots \ldots \ldots \ldots \ldots \ldots$

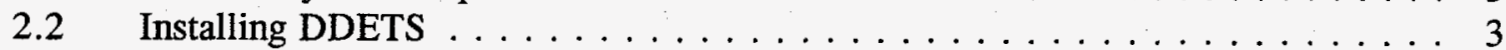

2.3 Executing DDETS $\ldots \ldots \ldots \ldots \ldots \ldots \ldots \ldots \ldots \ldots \ldots \ldots$

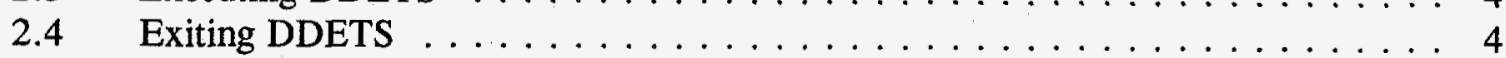

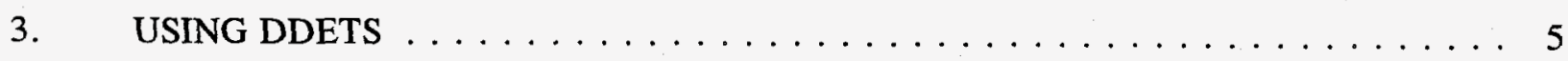

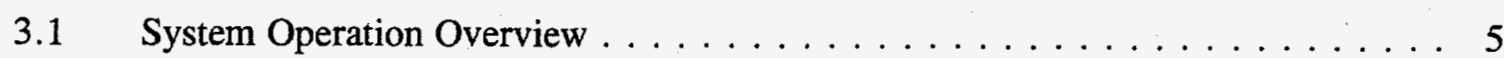

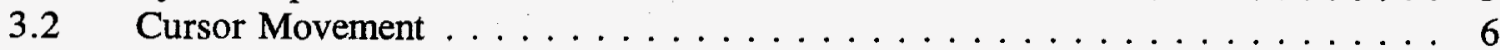

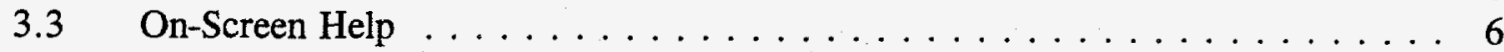

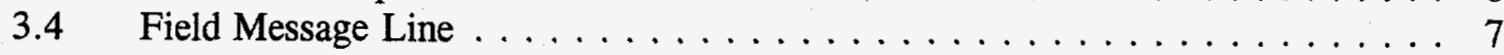

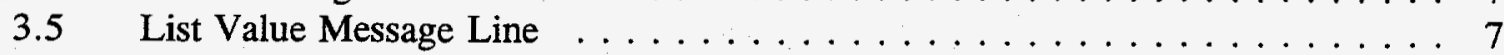

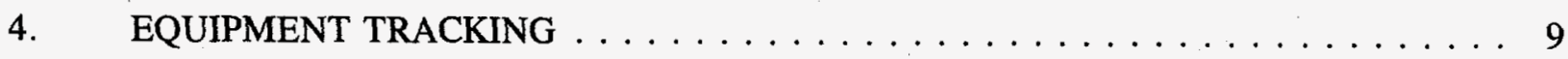

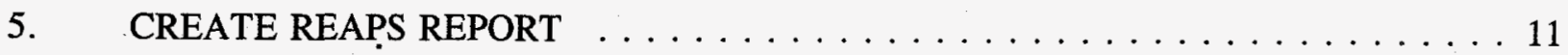

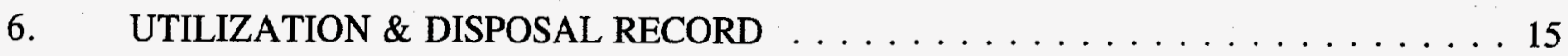

7. TRANSMIT REAPS DATA $\ldots \ldots \ldots \ldots \ldots \ldots \ldots \ldots \ldots \ldots \ldots \ldots$

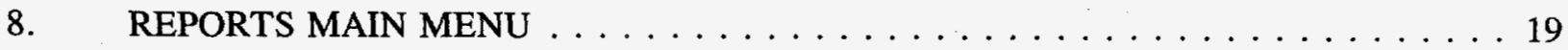

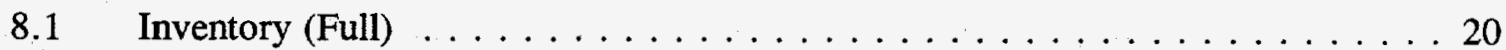

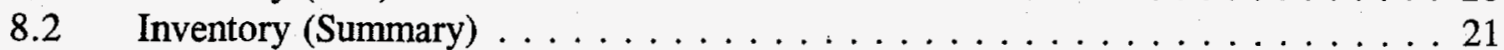

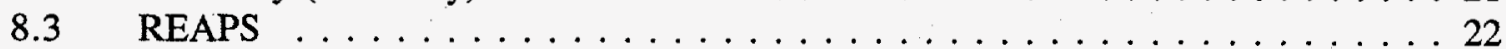

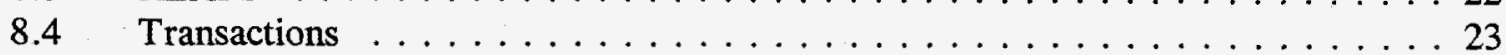

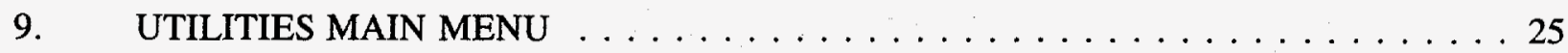

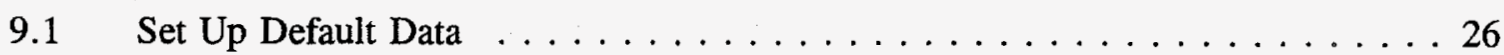

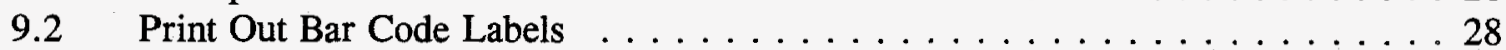

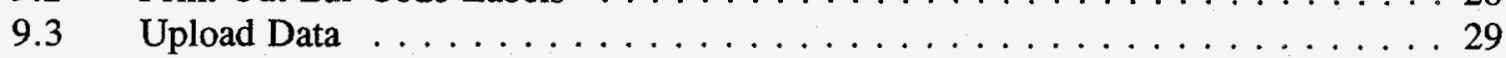

9.4 Back Up DDETS Data . . . . . . . . . . . . . . . . . . . 29 
(THIS PAGE INTENTIONALLY LEFT BLANK) 


\section{LIST OF FIGURES}

\section{$\underline{\text { Page }}$}

1. DDETS Main Menu $\ldots \ldots \ldots \ldots \ldots \ldots \ldots \ldots \ldots \ldots \ldots \ldots$

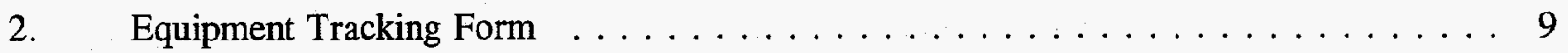

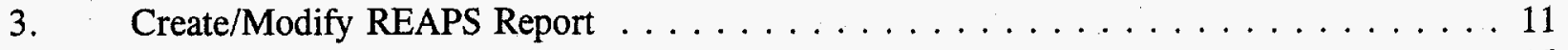

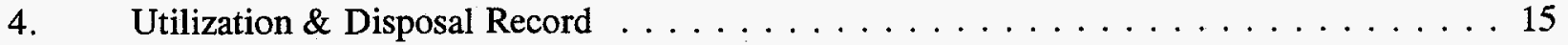

5. Reports Main Menu . . . . . . . . . . . . . . . . . . . . . . 19

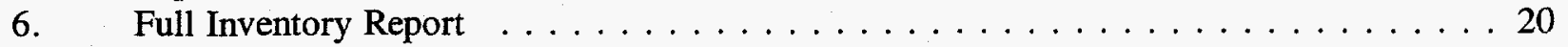

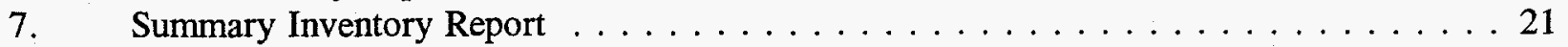

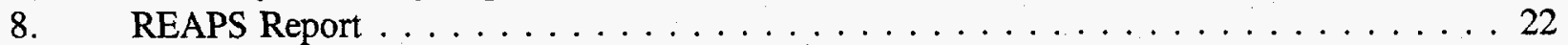

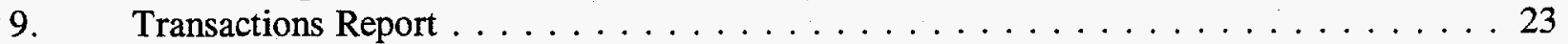

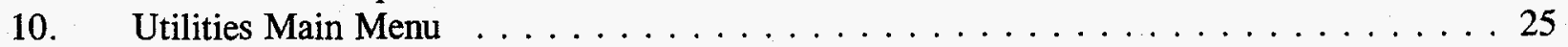

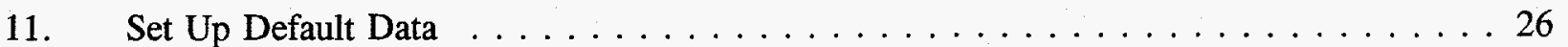

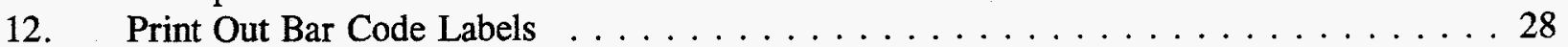

13. Back Up DDETS Data . . . . . . . . . . . . . . . . . . . . . . . 29 
(THIS PAGE INTENTIONALLY LEFT BLANK) 


\section{INTRODUCTION}

At the request of the Department of Energy (DOE)(EM-50), the Scientific Computing Unit developed a prototype system to track information and data relevant to equipment and tooling removed during decontamination and decommissioning activities. The DDETS proof-of-concept tracking system utilizes a one-dimentional (1D) and two-dimensional (2D) bar coding technology to retain and track information such as identification number, manufacturer, requisition information, and various contaminant information, etc. The information is encoded in a bar code, printed on a label and can be attached to corresponding equipment.

The DDETS was developed using a proven relational database management system which allows the addition, modification, printing, and deletion of data. In addition, communication interfaces with bar code printers and bar code readers were developed. Additional features of the system include:

- $\quad$ Four different reports available for the user (REAPS, transaction, and two inventory)

- Remote automated inventory tracking capabilities

- Remote automated inventory tracking capability (2D bar codes allow equipment to be scanned/tracked without being linked to the DDETS database)

- $\quad$ Edit, update, delete, and query capabilities

- On-line bar code label printing utility (data from 2D bar codes can be scanned directly into the data base simplifying data entry), and

- Automated data backup utility.

Compatibility with the Reportable Excess Automated Property System (REAPS) to upload data from DDETS is planned.

\subsection{Software Development}

This software and documentation was developed by the Idaho National Engineering Laboratory under contract to the U.S. DOE, Idaho Operations Office. Any comments or questions pertaining to the software should be directed to the following individuals:

Scott D. Cook

Idaho National Engineering Laboratory

EG\&G Idaho, Inc.

Scientific Computing Unit

P.O. Box 1625

Idaho Falls; ID 83415-3730

Marie B. Larsen

Idaho National Engineering Laboratory

EG\&G Idaho, Inc.

Scientific Computing Unit

P.O. Box 1625

Idaho Falls, ID 83415-3730
Phone: (208) 526-5167

Fax: (208) 526-9908

Phone: (208) 526-5881

Fax: (208) 526-9908 


\subsection{Software Notice}

This system was sponsored and funded by an agency of the United States Government. Neither the United States Government, nor any agency or contractor thereof, or any of their employees makes any warranty, expressed or implied, or assumes any legal liability or responsibility for any third party's use, or the results of such use, or any information, apparatus, product or process. 


\section{GETTING STARTED}

\subsection{DDETS System Requirements}

DDETS runs in a single-user environment. The system can retain as many records as the hard disk can accommodate.

Running the DDETS software requires the following:

- IBM personal computer (PC) 386, or compatible

- $\quad$ Microsoft-DOS v3.3 or higher

- Oracle v6.0 database and tools

- $6 \mathrm{MB}$ of random access memory (RAM)

- $3 \frac{1}{2}$ inch floppy-disk drive for loading the DDETS software

- Hard drive with a minimum of $15 \mathrm{MB}$ free disk space during installation and program use

- $\quad$ LaserJet Printer

- A/B Switch Box

- Zebra Stripe Model 500 Bar Code Printer

- Symbol PDF1000 2D Bar Code Scanner

\subsection{Installing DDETS}

The DDETS software is easy to install. A special install command creates a directory on the PC hard drive (C:IDDETS) and copies the DDETS files from the floppy disk to the hard drive's new directory.

Note: The user must first install the Oracle v6.0 database and tools and have them up and running prior to installing the DDETS software.

1. Place the DDETS installation disk into a $3 \frac{1}{2}$ inch floppy disk drive.

2. At the $\mathbf{C}: \backslash>$ screen prompt, type A: and press ENTER. The A: $\backslash>$ prompt will appear.

3. Type INSTALL and press ENTER. 


\subsection{Executing DDETS}

The user must first install the Oracle v6.0 database and tools on the $C: \backslash$ drive of the PC and have it up and running before attempting to execute DDETS. Once Oracle has been installed, the user can invoke it by either typing ORACLE from the DOS prompt (C:IDOS $>$ ) each time the PC is turned on or by adding IC:|ORACLE6|ORACLE to the AUTOEXEC.BAT file on the PC.

To run the DDETS software type CDIDDETS and press ENTER. The prompt should appear C:LDDETS $>$. The user must now type DDETS and press ENTER to bring up the DDETS Main Menu (Figure 1).

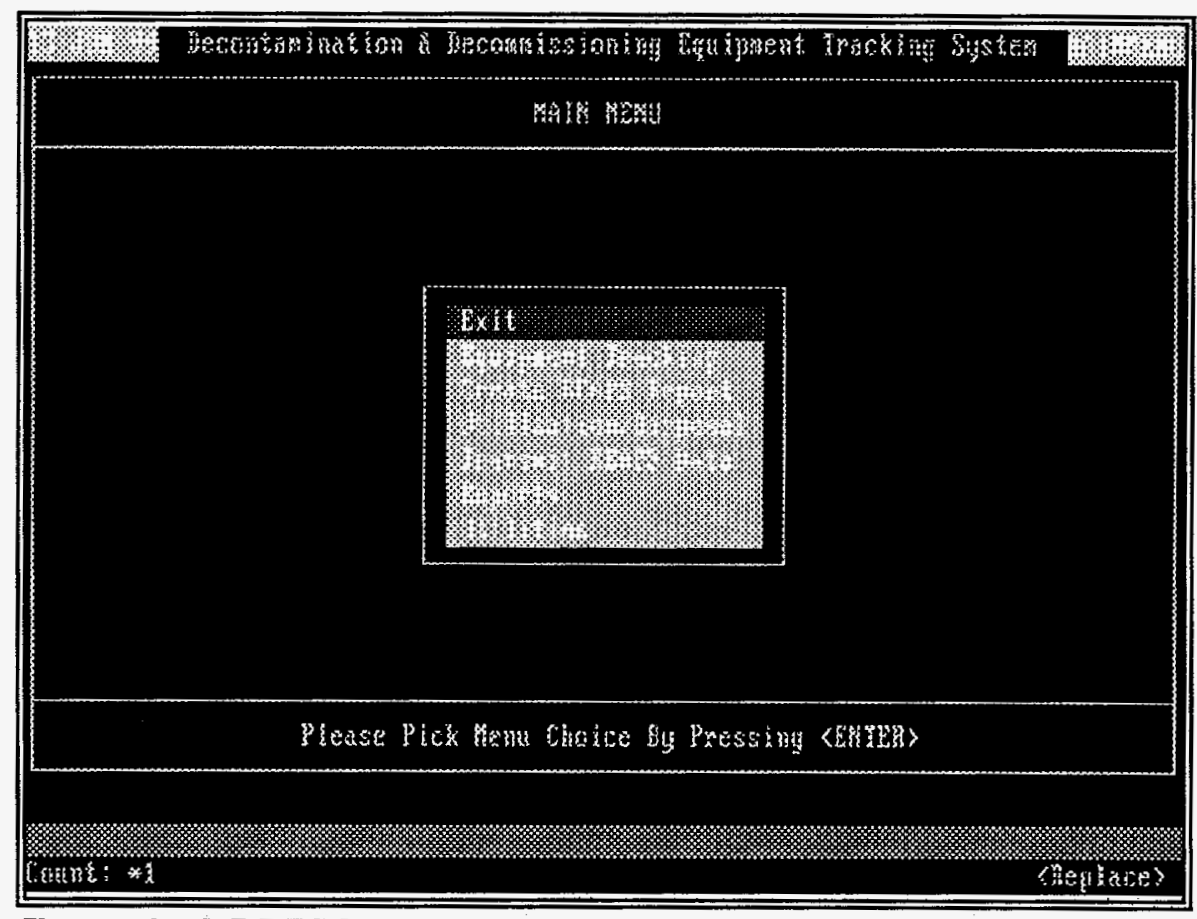

Figure 1. DDETS Main Menu

\subsection{Exiting DDETS}

To exit DDETS, the user can select EXIT from the main menu or repeatedly press the ESC (escape) key from the other screens. When using ESC, users should follow the prompts to save data as each screen is exited. The user will only be prompted to save data if information has been input to a screen. 


\section{USING DDETS}

DDETS is designed to track information and data relevant to equipment and tooling removed during decontamination and decommissioning activities. The DDETS system provides the user with a variety of automated forms and reports to facilitate equipment status, tracking, and compliance to regulations. The Equipment Tracking form allows the user to enter new information specific to each piece of equipment or to recall records already input to the system. The Create/Modify REAPS Report allows the user to input information, or load default information. The system allows the user the option of printing bar codes for new information at the time of entry or at a later date. The Utilization/Disposal Report documents the disposition of any piece of equipment. The Transmit REAPS Data function, with future development, will allow the user to upload the DDETS REAPS Report data to the governmental REAPS report. Inventory and transactions reports are available through the Reports Menu. Finally, setting default data, printing bar codes, uploading data, and back up functions are available through the Utility Menu.

\subsection{System Operation Overview}

\subsubsection{Software Installation}

The user must first install the Oracle 6.0 database and tools on the $C: \backslash$ drive of the PC and have the software up and running before attempting to execute DDETS. Once Oracle has been installed, the user can invoke it by either typing ORACLE or by adding IC:IORACLE6\ORACLE to the AUTOEXEC.BAT file on the PC.

\subsubsection{Enabling the Bar Code Printer and Scanner}

SETPORTS must be typed from the C:IDDETS > prompt prior to typing DDETS. The user will be prompted by the system to identify the ports that connect the bar code printer and scanner on the PC.

\subsubsection{Running DDETS}

Oracle must be invoked and the printer and scanner ports identified prior to running the Decontamination and Decommissioning Equipment Tracking System (DDETS).

To run the DDETS software, type DDETS from the C:LDETS > prompt and press ENTER. This will bring up the DDETS Main Menu on screen (Figure 1). 


\subsection{Cursor Movement}

The ESC (escape) key allows the user to back out of the system one screen at a time. The Esc key also allows the user to back out of any screen or pop-up menu without committing changes.

The user can move throughout the main menus or pop-up menus by using the UP-ARROW or DOWN-ARROW and then pressing the ENTER key on a highlighted category. The user can move throughout the form fields to enter information by using the ENTER and TAB keys. The SHIFT-TAB key moves the cursor back through the form fields in the opposite direction.

A mouse is not operational with the DDETS system.

\subsection{On-Screen Help}

On-screen help is available to the user in the DDETS system. The user can access the on-screen help from any location in the system. The three types of on-screen help available are key stroke, initiate query, and execute query commands.

\subsection{1 < Ctrl-k > - List of Available Key Strokes}

When the user presses the CONTROL and $\mathbf{K}$ keys simultaneously, an alphabetical list of the functions available to the user and the associated key strokes appear on the screen. The user can scroll through the function list by using the UP-ARROW or DOWN-ARROW. Use the ESC key to return to the screen from which the $<$ Ctrl- $\mathrm{k}>$ command was invoked.

\subsection{2 < F7 > - Initiate Query}

When the cursor is on a field and the user presses F7, a query on the field is initiated. The user is then able to type in the search criteria relative to the field. The user then presses $\mathbf{F 8}$ to execute the query.

\subsection{3 < F8 > - Execute Query}

Press F8 to execute a query after initializing a query and typing in the search criteria. The system will locate all the records meeting the search criteria. The user can then scroll through the records using the PgDn - Next Record and PgUp - Previous Record keys. Use the ESC key to return to the screen from which the query command $(<\mathrm{F} 8\rangle$ ) was invoked. 


\subsection{Field Message Line}

Field messages have been designed into the DDETS system to assist the user in completing forms as easily and concisely as possible. The field message line is located across the bottom of the screen. As the user moves through the various fields, the system displays a field message line with information relevant to the field in which the cursor resides. It provides "quick help" information about a field.

\subsection{List Value Message Line}

A list value message line has been designed into the system to inform the user that the highlighted field has a pick-list available. The list value message line is located in the right corner beneath the field message line and appears in brackets; < List >. Press F9 to invoke the pick-list by pressing F9. When the pick-list appears, the user highlights the item to be inserted into the field and presses ENTER. The system automatically places the selected item into the field that was highlighted when the user invoked the $\langle$ List $>$ command. If the user decides not to select any items from the pick-list, ESC can be pressed to remove the pick-list from the screen. The user can then type the desired information into the field. 
(THIS PAGE INTENTIONALLY LEFT BLANK) 


\section{EQUIPMENT TRACKING}

The Equipment Tracking form is used to track equipment that is to be decontaminated, decommissioned, or transferred. The information entered into this form can be uploaded to the REAPS report at a future date. To access the form the user must highlight Equipment Tracking on the DDETS Main Menu and press ENTER (Figure 2).

When the user selects the Equipment Tracking form, a pop-up message overlays the form asking the user, "Print bar codes for new items entered into the database?" The user types "Y" and presses ENTER for bar codes to be printed or " $\mathbf{N "}$ and presses ENTER to simply add new information. The system then removes the pop-up message allowing the user to enter information.

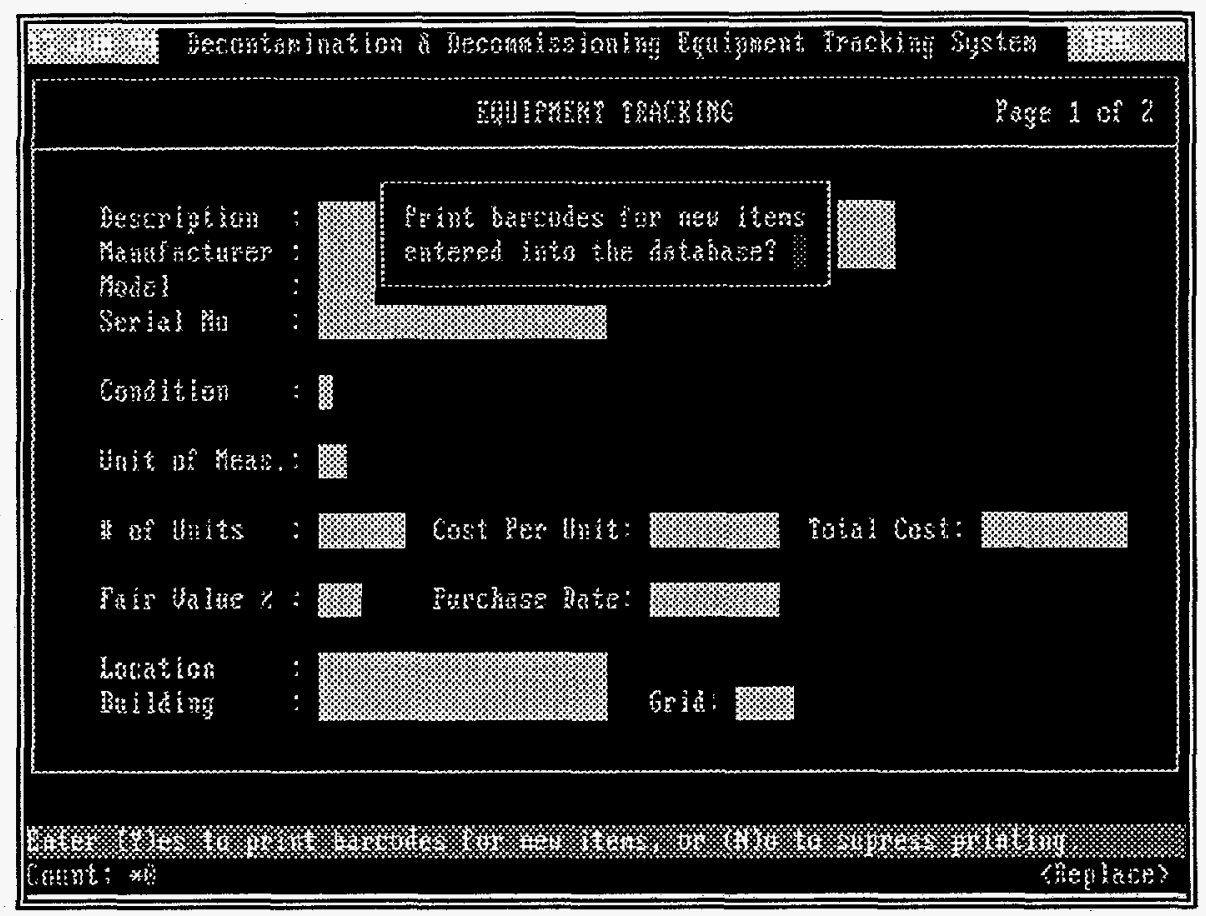

Figure 2. Equipment Tracking Form

(Page 1 of 2) 


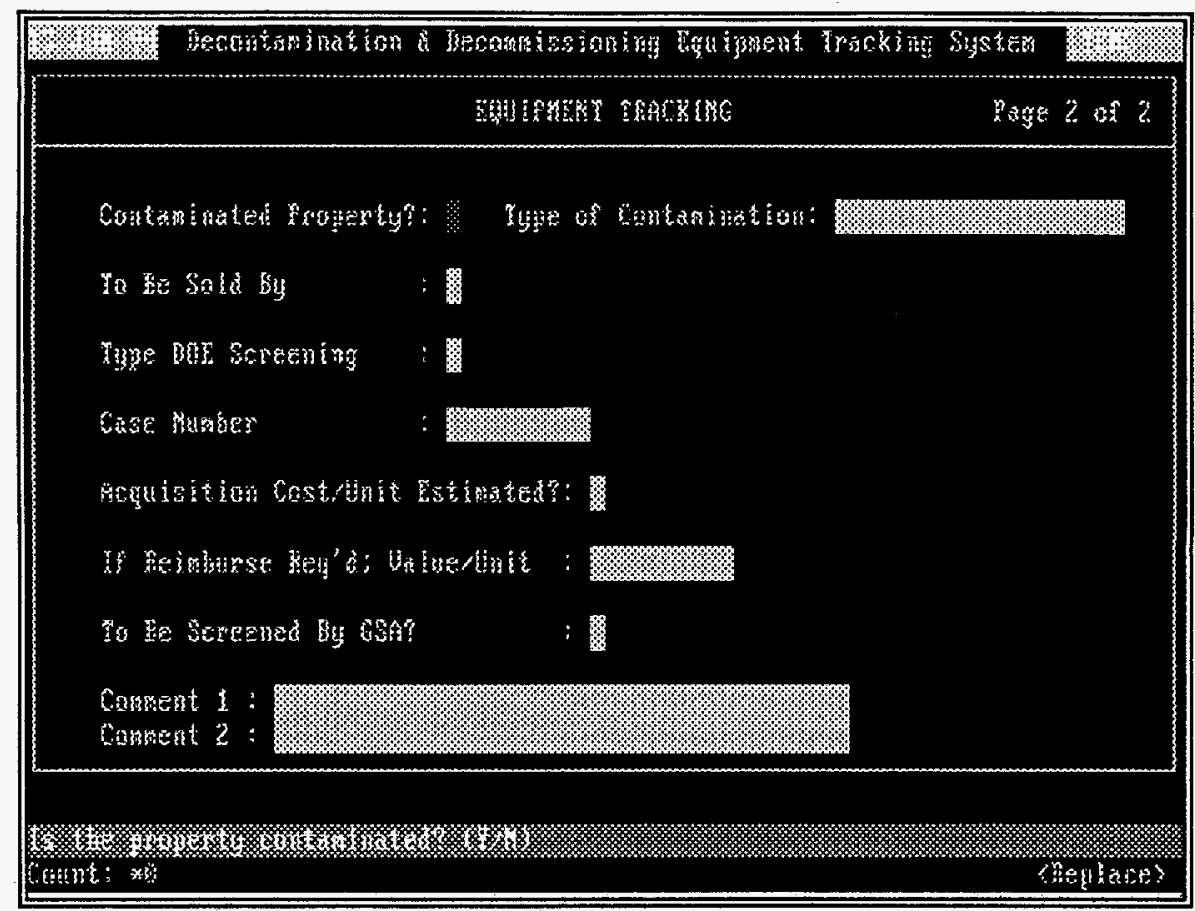

Figure 2. Equipment Tracking Form

(Page 2 of 2)

New information can now be entered into the blank form or the user can press "F8" to bring up previously entered records. The user can scroll through the records by pressing the PgUp or PgDn keys. Once a record has been called up, the information contained in it can be modified by typing in new information and pressing F10 to save the information. The Esc key can be used if the user does not wish to commit changes or to bring back the blank Equipment Tracking form. 


\section{CREATE REAPS REPORT}

The Create/Modify REAPS Report captures data necessary to upload and generate the DDETS REAPS report. It enables the user to electronically tag equipment (previously input to the Equipment Tracking form) for importing to the Create/Modify REAPS Report.

When the user selects CREATE REAPS REPORT from the DDETS Main Menu, a pop-up message overlays the form asking the user, "Would you like to load the default data?" The user types "Y" and presses ENTER to recall previously entered default data or "N" and presses ENTER to simply add new information. The default data is shipping information that is frequently used. The user sets the default data from the DDETS Utility functions (see Section 9.1 for specific instructions). The system then removes the pop-up message and brings up the default data or the blank form to allow the user to enter information (Figure 3). The information needed to complete this form is: The report number, date mailed, total cost, type of report, shipped to, fund to be reimbursed, shipped from, point-of-contact, agency approval, GSA control number, FSC group number, address for disposal instructions, location of property, agency control number, property abandon date, and surplus release date.

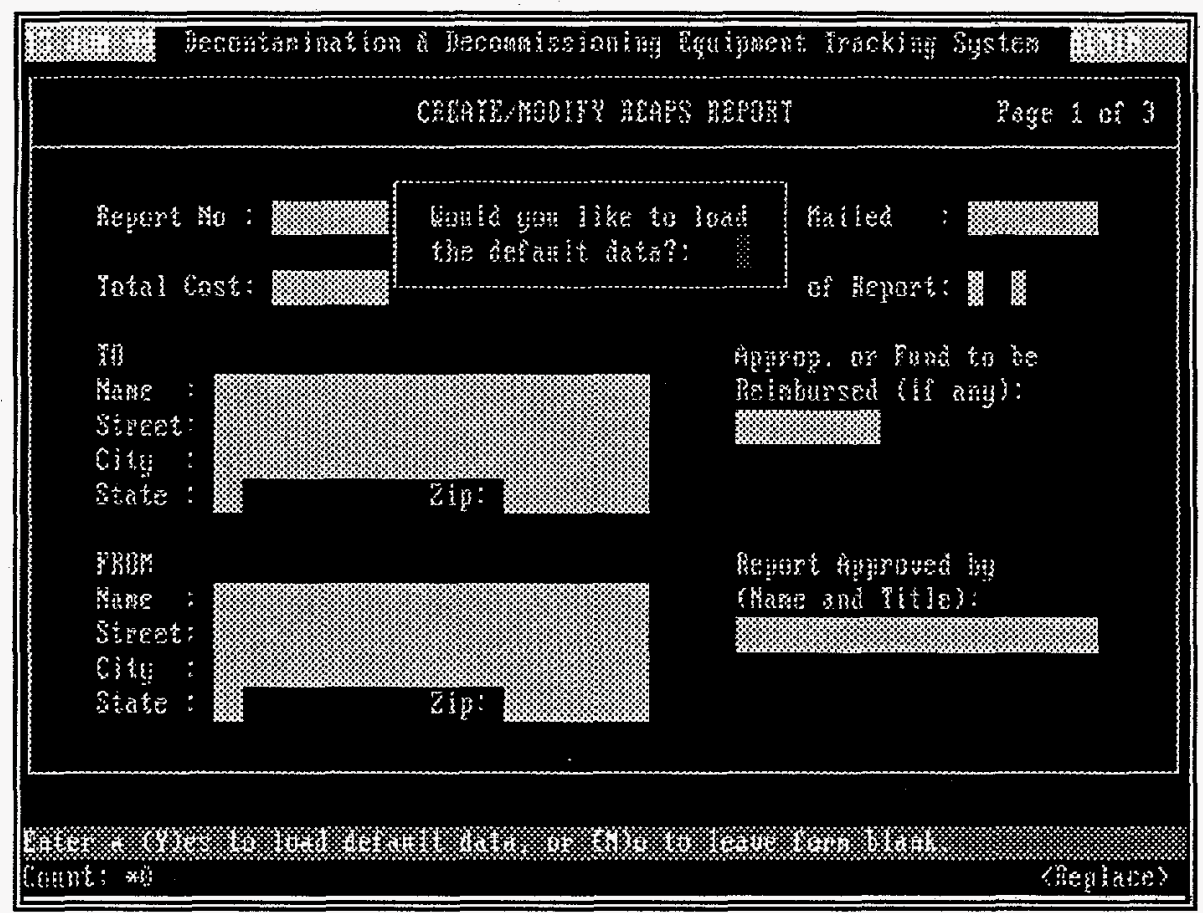

Figure 3. Create/Modify REAPS Report

(Page 1 of 4) 


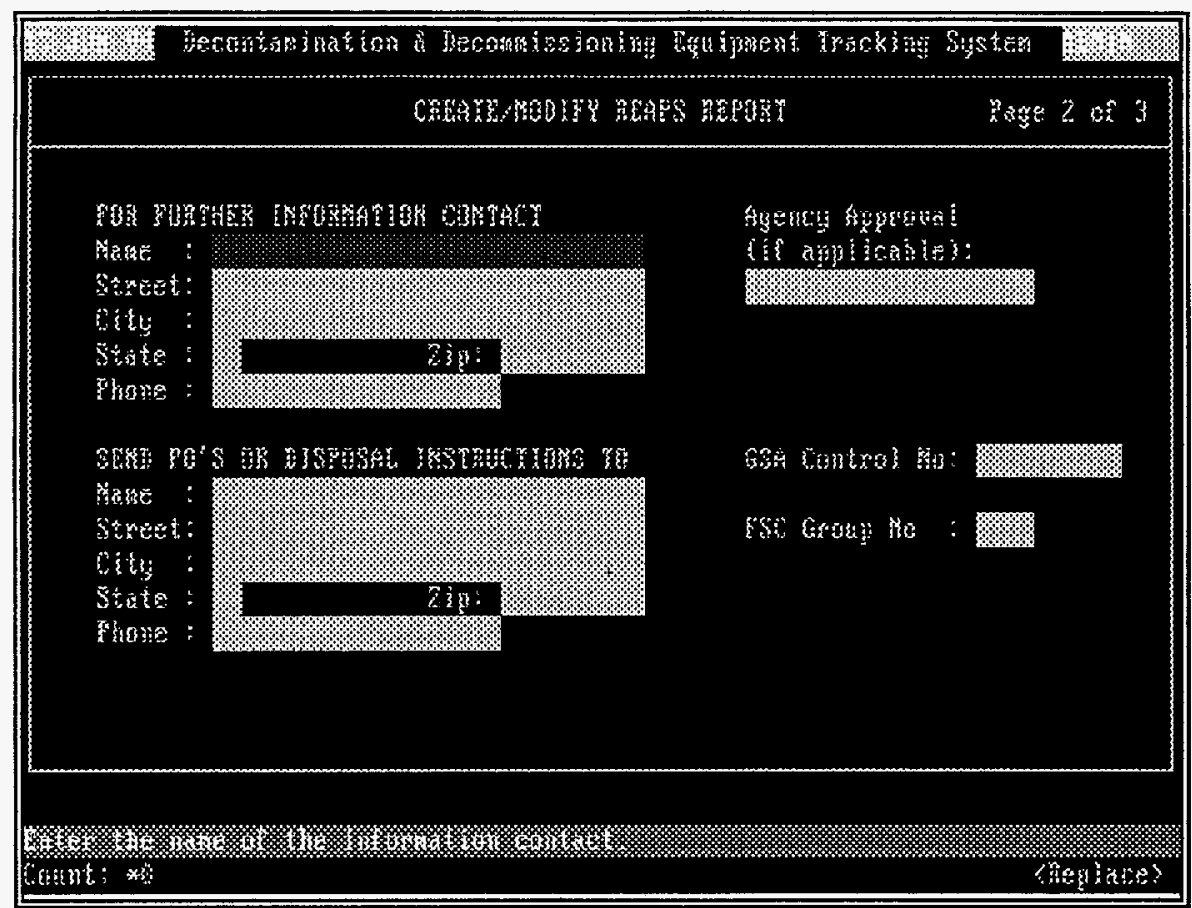

Figure 3. Create/Modify REAPS Report

(Page 2 of 4)

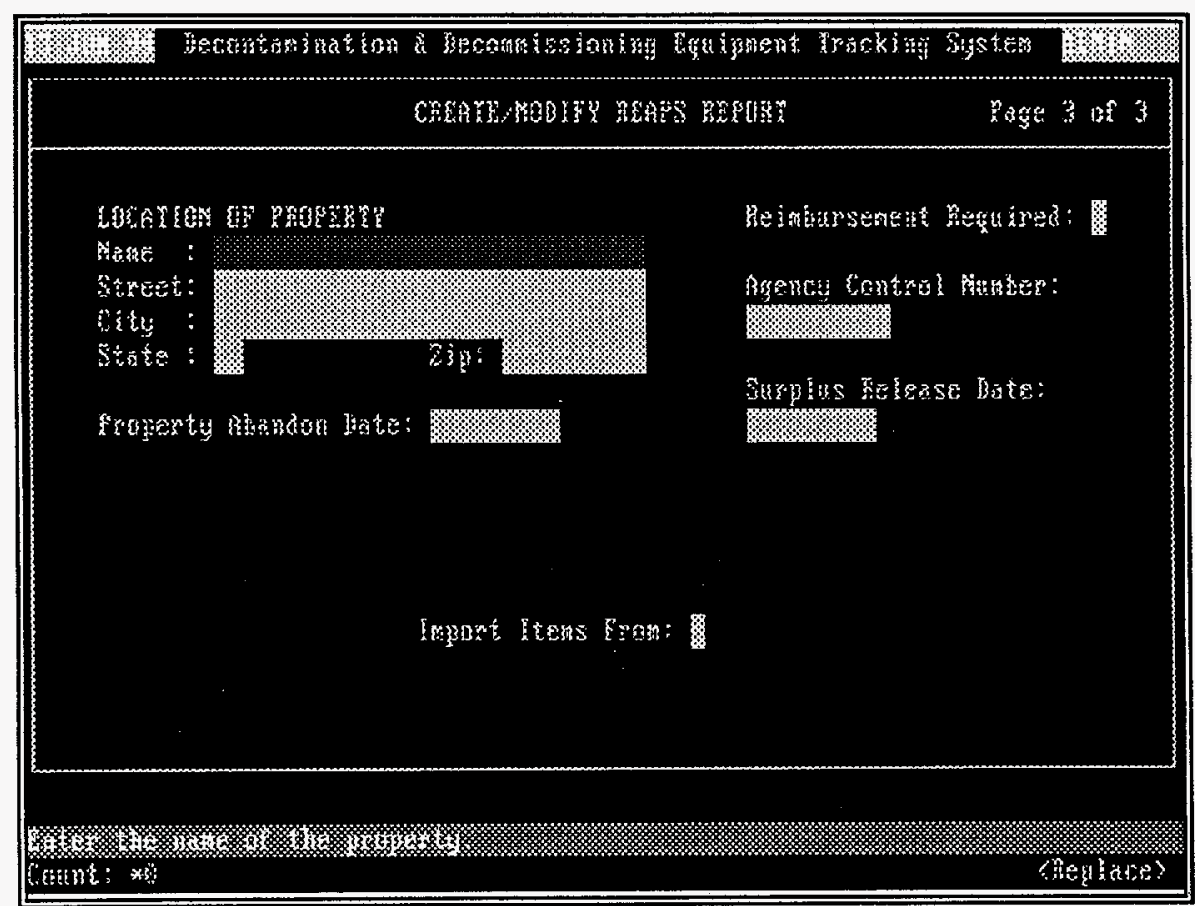

Figure 3. Create/Modify REAPS Report

(Page 3 of 4) 
The user identifies the equipment to be removed or relocated during decontaminating or decommissioning on page 3 of the form. The system prompts the user for a code. If the user enters code "A", a pop-up screen listing all available equipment appears. The user then electronically tags the appropriate equipment. This information is automatically linked to the Create/Modify REAPS report. Once the user has input the information, F10 (Accept) must be pressed.

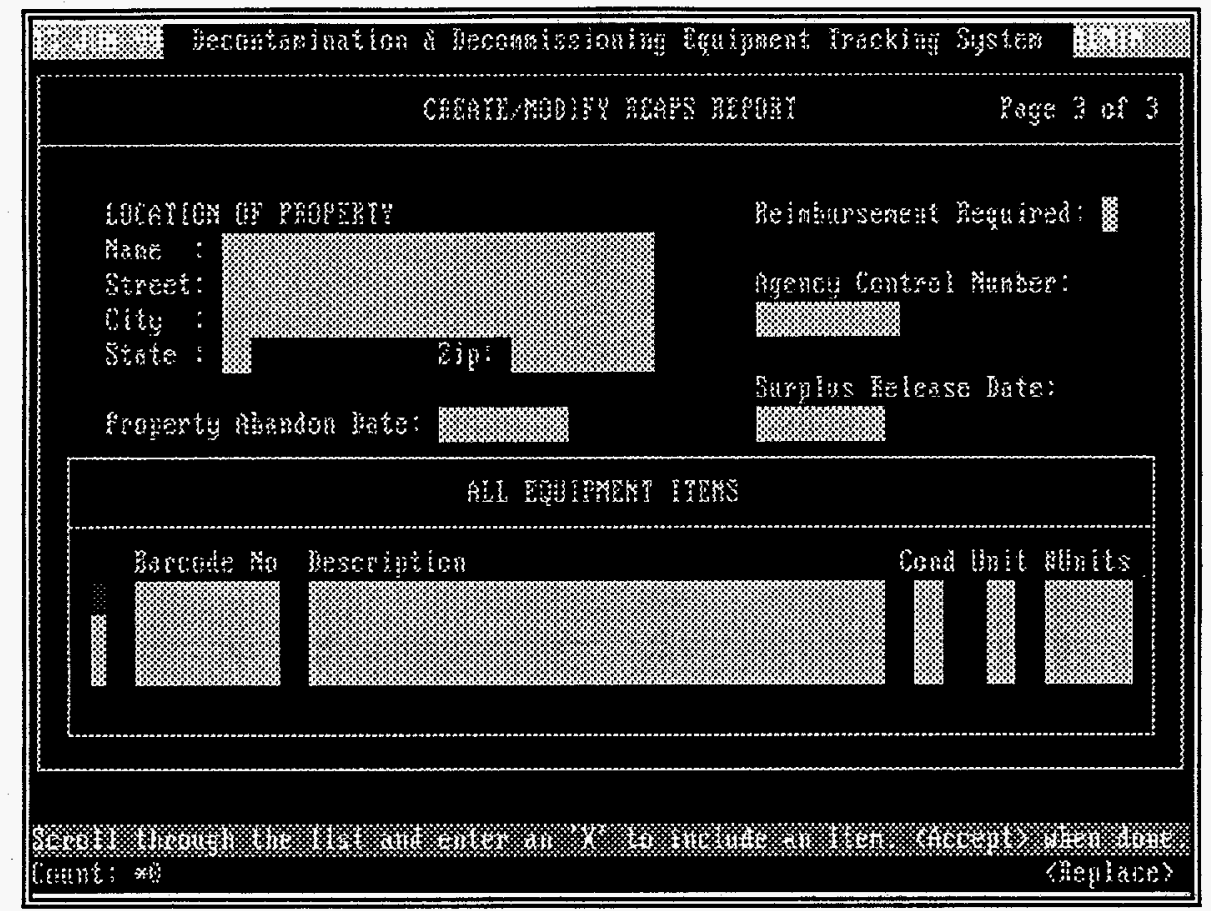

Figure 3. Pop-Up Screen for Create/Modify REAPS Report (Page 4 of 4)

If the user enters code "B", the system waits for the user to scan the bar code from the equipment. This information is automatically linked to the Create/Modify REAPS report. Once the user has input the information, F10 (Accept) must be pressed. 
(THIS PAGE INTENTIONALLY LEFT BLANK) 


\section{UTILIZATION \& DISPOSAL RECORD}

The Utilization \& Disposal Record form is used to input information to the DDETS system when an individual/agency calls and requests information on a piece of equipment. The user inputs data necessary to identify the requester and track the disposition of the equipment. This form also enables the user to electronically tag equipment (previously input to the Equipment Tracking form) and the associated bar code to import to the form.

When the user selects UTILIZATION/DISPOSAL from the DDETS Main Menu, the system brings up the blank form to allow the user to enter information (Figure 4). The user can obtain an equipment listing/ associated bar code to fill the first field (bar code number) by pressing F9, highlighting the appropriate equipment by use of the UP-ARROW and DOWN-ARROW, and then pressing ENTER. The system automatically inserts the bar code for the electronically selected equipment. The Quantity Affected field is an automatic calculation field. When a piece of equipment is tagged to be shipped, the system automatically removes it from the system equipment inventory. The other information needed to complete this form is: The transaction ID, quantity affected, requester/recipient, freeze information, final disposition information, extended surplus release date, and transaction date. Once the user has input the information, F10 (Accept) must be pressed.



Figure 4. Utilization \& Disposal Record

To print a report using information input from this form (see Section 8.4, Transaction Report). 
(THIS PAGE INTENTIONALLY LEFT BLANK) 


\section{TRANSMIT REAPS DATA}

This function is not yet available.

The system brings up a pop-up message of "This option has not yet been completed. Press <ENTER > to continue..." After pressing ENTER, the user is brought back to the DDETS Main Menu.

The Transmit REAPS Data will allow the user to upload information from the DDETS REAPS Report to the other government agency REAPS reports. The DDETS REAPS report was structured to be compatible for uploading information. 
(THIS PAGE INTENTIONALLY LEFT BLANK) 


\section{REPORTS MAIN MENU}

The Reports forms provide an automated method to accurately and concisely status and track equipment information.

When the user selects REPORTS from the DDETS Main Menu, the system brings up the Reports Menu (Figure 5). The user then selects the type of report to be generated; Inventory (Full), Inventory (Summary), REAPS, or Transactions. The information needed by the user to input to the report forms varies. Please see the specific report section (Sections $8.1,8.2,8.3$, or 8.4) for more detailed information.

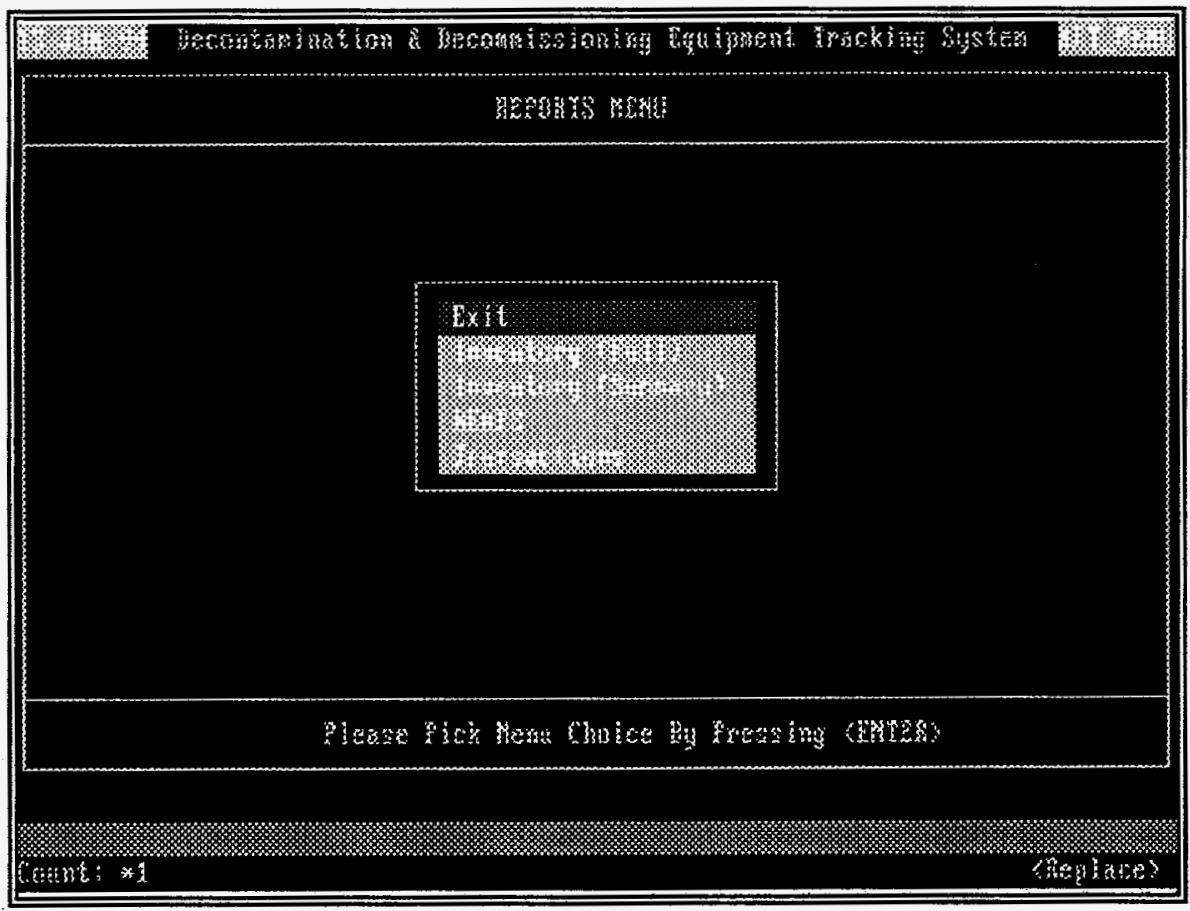

Figure 5. Reports Main Menu 


\subsection{Inventory (Full)}

The Full Inventory report is a one-page per item report that identifies all information in the DDETS system associated with an item. After the user selects the report, a pop-up screen overlays the Full Inventory report asking the user if the report is to be printed to a file, printer, or to the screen. If File is selected, the user is prompted for a file name. If Printer is selected, the report prints to the user's printer. If Screen is selected, the report prints to the screen. After the print location is identified, the system removes the pop-up screen. The user must next identify the bar code number of the equipment to be inventoried (Figure 6). By pressing F9 the system brings up a pop-up list of equipment and associated bar codes. The user can then highlight the appropriate piece of equipment by use of the UPARROW or DOWN-ARROW key. Press ENTER to select and F10 to execute. The system automatically inserts the selected bar code into the Full Inventory report form. If the user wants a Full Inventory report on all equipment in the system, the bar code number field can be left blank when the user presses ENTER.

The information included in this report is: The bar code number, report number, description, manufacturer, model, serial number, condition, date purchased, location, building, grid, unit, number of units, cost per unit, total cost, fair value, contaminated property, type of contamination, to be sold by, type DOE screening, case number, cost unit estimated, reimburse value per unit, and to be screened by GSA.

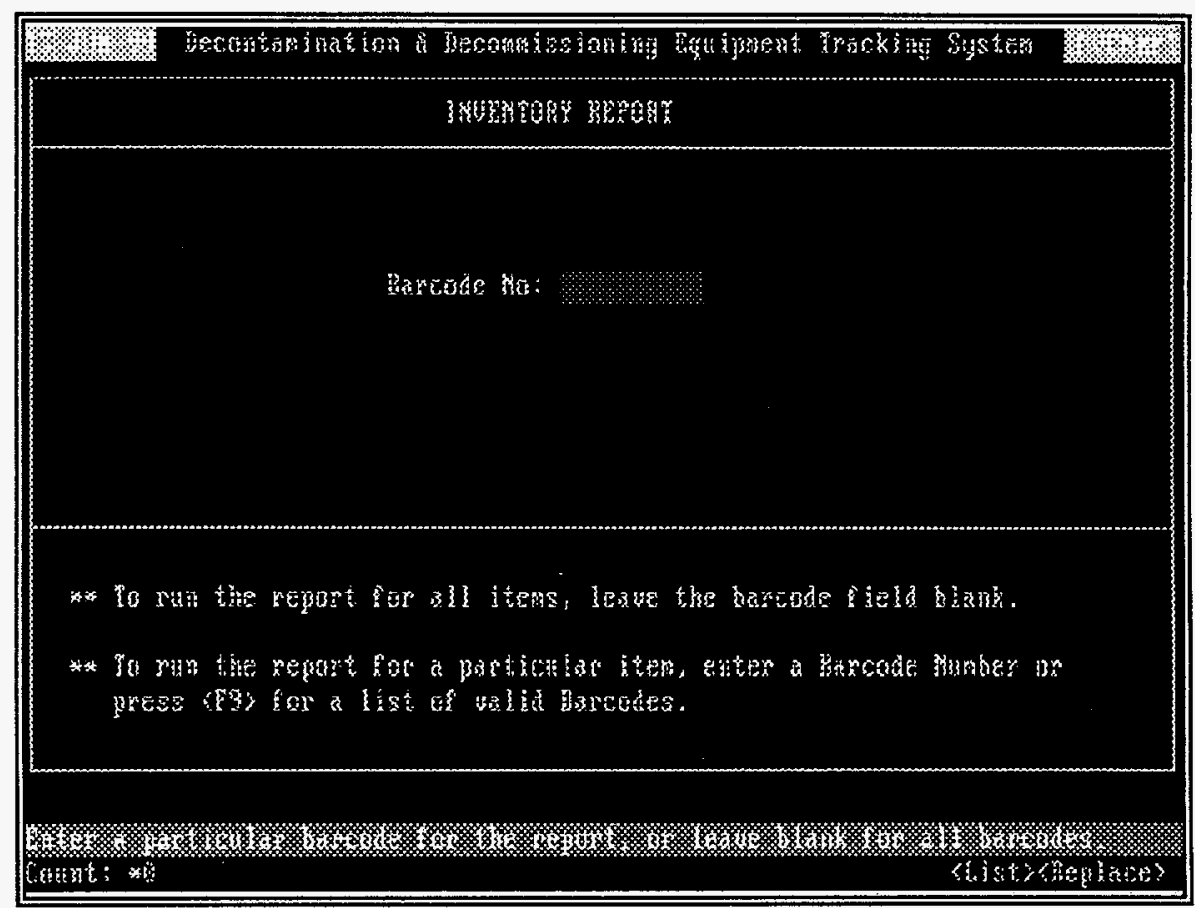

Figure 6. Full Inventory Report 


\subsection{Inventory (Summary)}

The Summary Inventory report is a several-items-per-page report with summarized information associated with an item. After the user selects the report, a pop-up screen overlays the Summary Inventory report asking the user if the report is to be printed to a file, printer, or to the screen. If File is selected, the user is prompted for a file name. If Printer is selected, the report prints to the user's printer. If Screen is selected, the report prints to the screen. After the print location is identified, the system removes the pop-up screen. The user must next identify the bar code number of the equipment to be inventoried (Figure 7). By pressing F9 the system brings up a pop-up list of equipment and associated bar codes. The user can then highlight the appropriate piece of equipment by use of the UPARROW or DOWN-ARROW key. Press ENTER to select, and F10 to execute. The system automatically inserts the selected bar code into the Summary Inventory report form. If the user wants a Summary Inventory report on all equipment in the system, the bar code number field can be left blank when the user presses ENTER.

The information included in this report is: The bar code number, description, location, building, grid, number of units, and level of contamination.

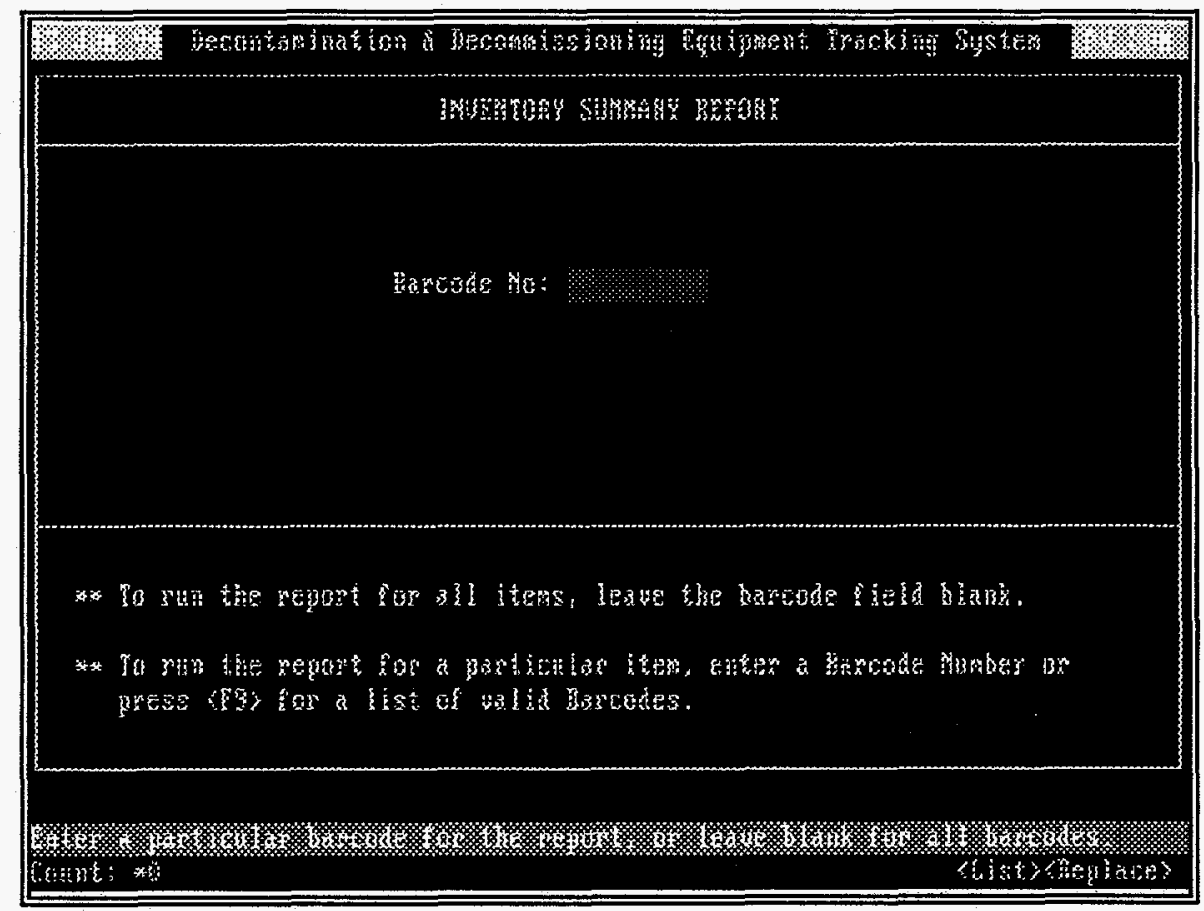

Figure 7. Summary Inventory Report 


\subsection{REAPS}

The DDETS REAPS (Report of Excess Personal Property) report (Figure 8) is an automated version of the manually prepared REAPS form currently in use by government agencies. The form is used to document shipment or disposal of government property and provides an auditable trail for compliance. After the user selects the report, a pop-up screen overlays the REAPS report asking the user if the report is to be printed to a file, printer, or to the screen. If File is selected, the user is prompted for a file name. If Printer is selected, the report prints to the user's printer. If Screen is selected, the report prints to the screen. After the print location is identified, the system removes the pop-up screen. The user must next identify the associated report number on which the equipment was decommissioned/ transferred. By pressing F9 the system brings up a pop-up list of report numbers previously assigned. The user can then highlight the appropriate report number by use of the UP-ARROW or DOWNARROW key. Press ENTER to select and F10 to execute. The system automatically inserts the selected report number. If the user wants a report on all equipment previously excessed, the report number field can be left blank when the user presses ENTER.

The REAPS report information includes: The report number, date mailed, total cost, type of report, to, from, point-of-contact for more information, sent to, location, abandon date, agency control number, fund to be reimbursed, report approved by, agency approval, GSA control number, FSC group number, reimbursement required, surplus release date, bar code number, description, condition, unit, number of units, cost per unit, total cost, fair value, contaminated, sold by, and DOE screen.

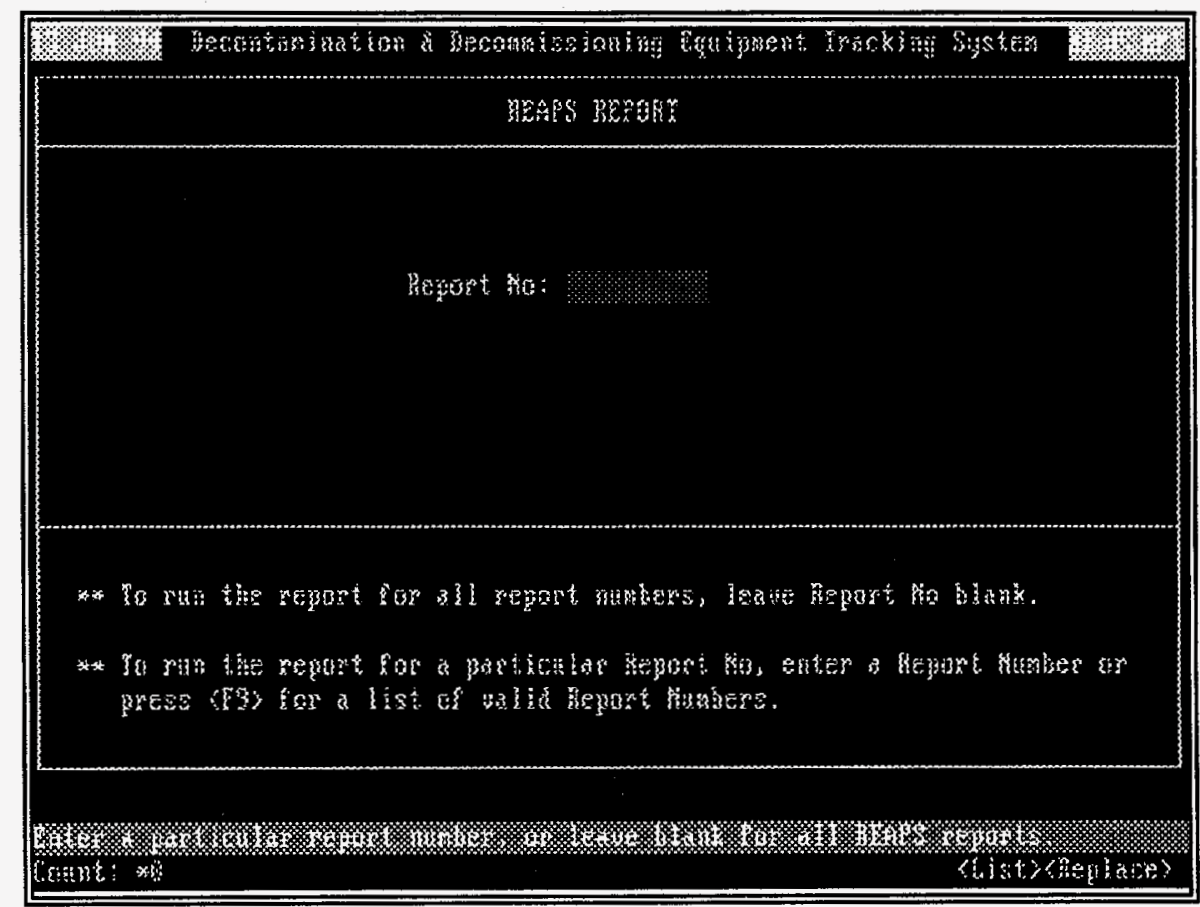

Figure 8. REAPS Report 


\subsection{TRANSACTIONS}

The Transactions Report is a several-items-per-page report that identifies information associated with an item (Figure 9). The information to generate this report is obtained from user input in the Utilization \& Disposal Record. After the user selects the report, a pop-up screen overlays the Transactions Report asking the user if the report is to be printed to a file, printer, or to the screen. If File is selected, the user is prompted for a file name. If Printer is selected, the report prints to the user's printer. If Screen is selected, the report prints to the screen. After the print location is identified, the system removes the pop-up screen. The user must next identify the bar code number of the equipment to be inventoried. By pressing $\mathbf{F 9}$ the system brings up a pop-up list of equipment and associated bar codes. The user can then highlight the appropriate piece of equipment by use of the UP-ARROW or DOWN-ARROW key. Press ENTER to select, and F10 to execute. The system automatically inserts the selected bar code. If the user wants a Transactions report on all equipment in the system, the bar code number field can be left blank when the user presses ENTER.

The information included in this report is: The bar code number, description, location, building, grid, number of units, and contamination.

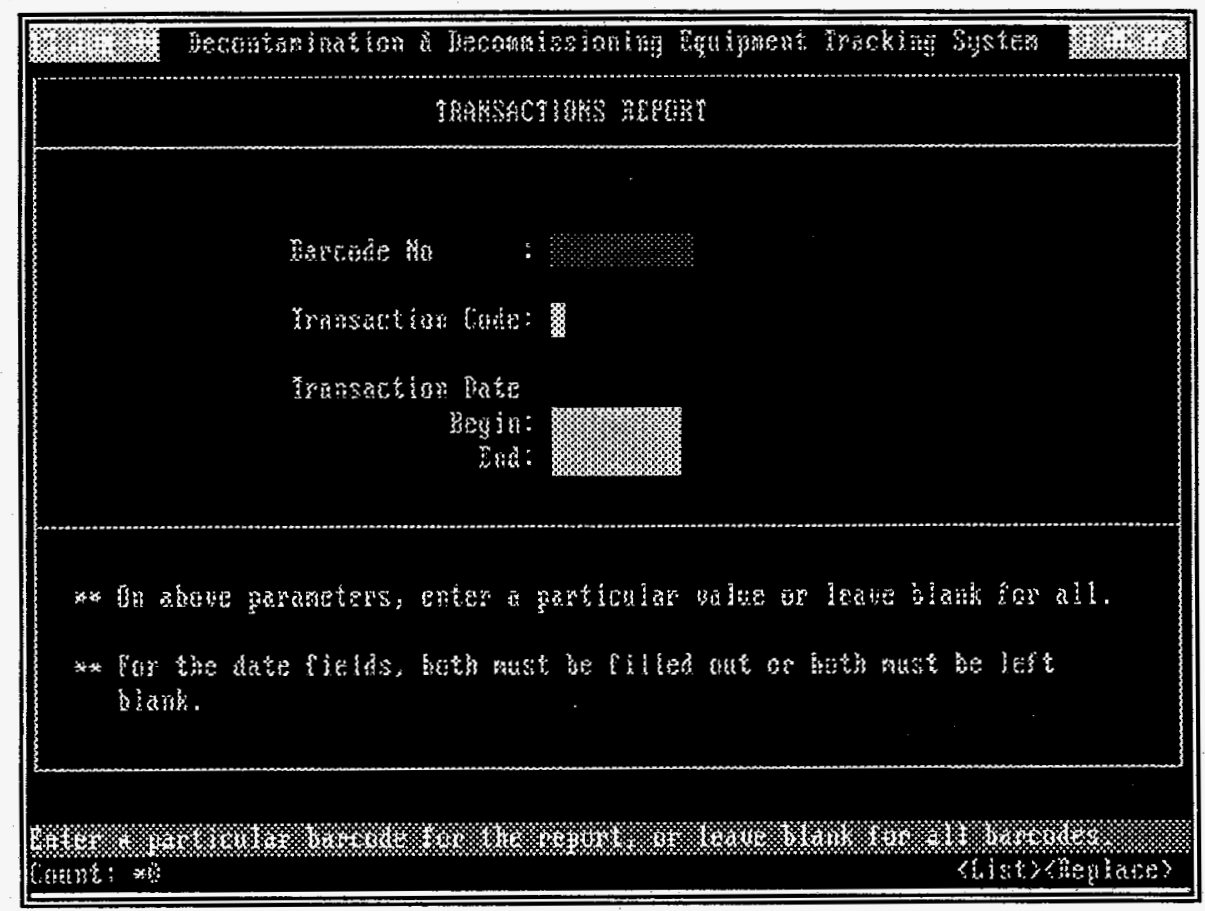

Figure 9. Transactions Report 
(THIS PAGE INTENTIONALLY LEFT BLANK) 


\section{UTILITIES MAIN MENU}

The Utilities Main Menu offers a variety of functions to make the DDETS system more versatile and user friendly.

When the user selects UTILITIES from the DDETS Main Menu, the system brings up the Utilities Menu (Figure 10). The user then selects the appropriate utility, sets up default data, prints bar code labels, uploads data, or backs up DDETS data.

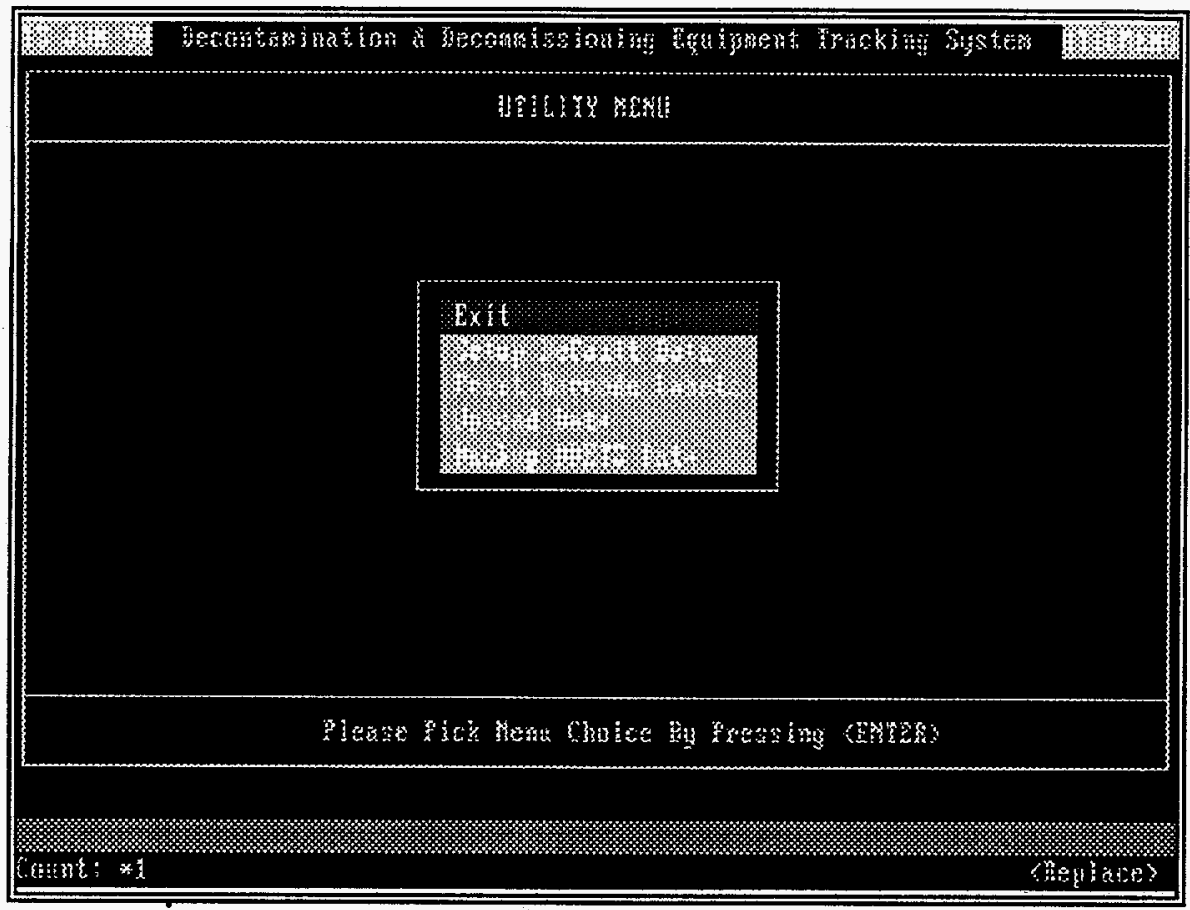

Figure 10. Utilities Main Menu 


\subsection{Set Up Default Data}

The Set Up Default Data Record allows the user to pre-identify the most frequently used ship to/from names and addresses information, point-of-contact, disposal instructions, and property location information for the Create/Modify REAPS Report. The system default will hold one name/address per category (Figure 11).

When the user selects the Create REAPS Report (Section 5.0) from the DDETS Main Menu, a pop-up screen will appear asking the user, "Would you like to load the default data?" If the user types "Y", the information pre-identified in Section 9.1, Set Up Default Data, will be loaded. This option saves time as the information does not have to be repeatedly retyped. The user can modify the default information at any time.

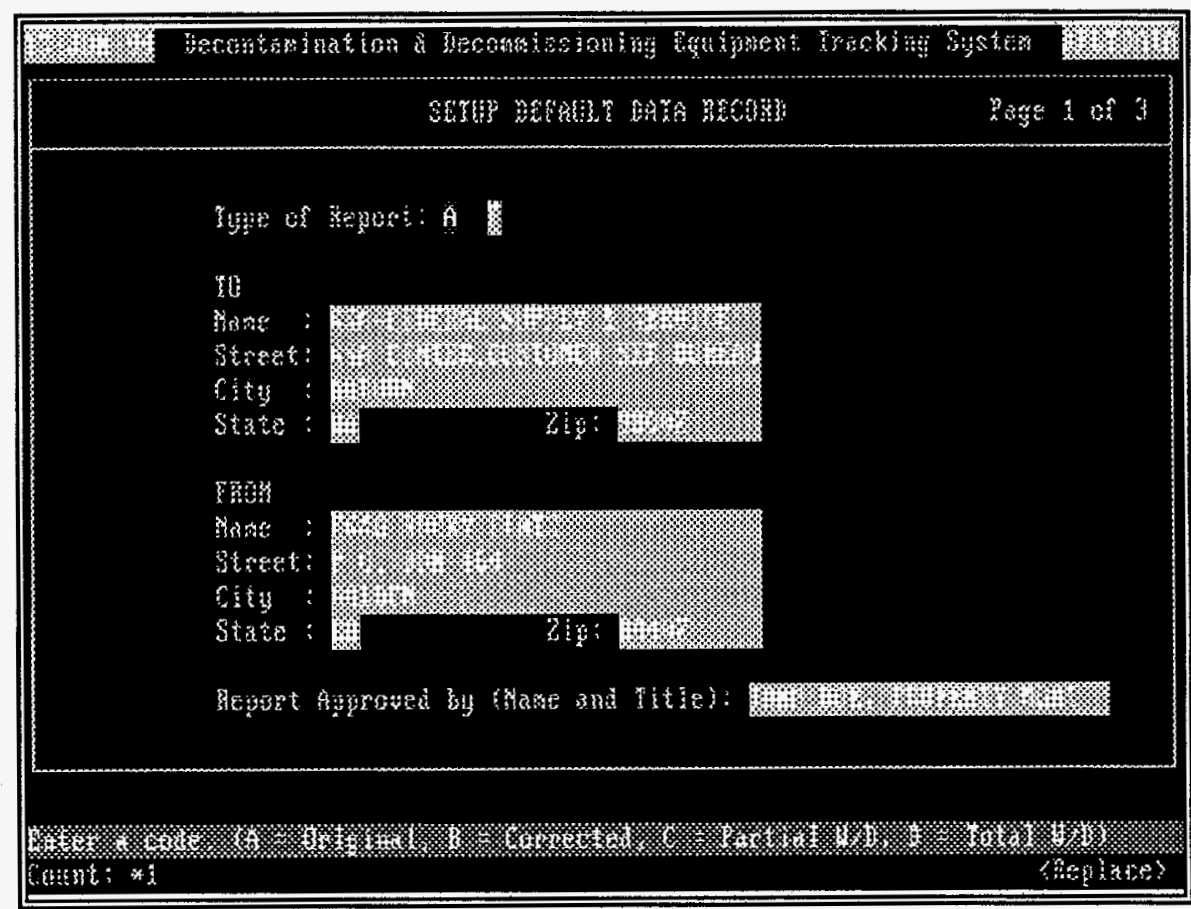

Figure 11. Set Up Default Data

(Page 1 of 3) 

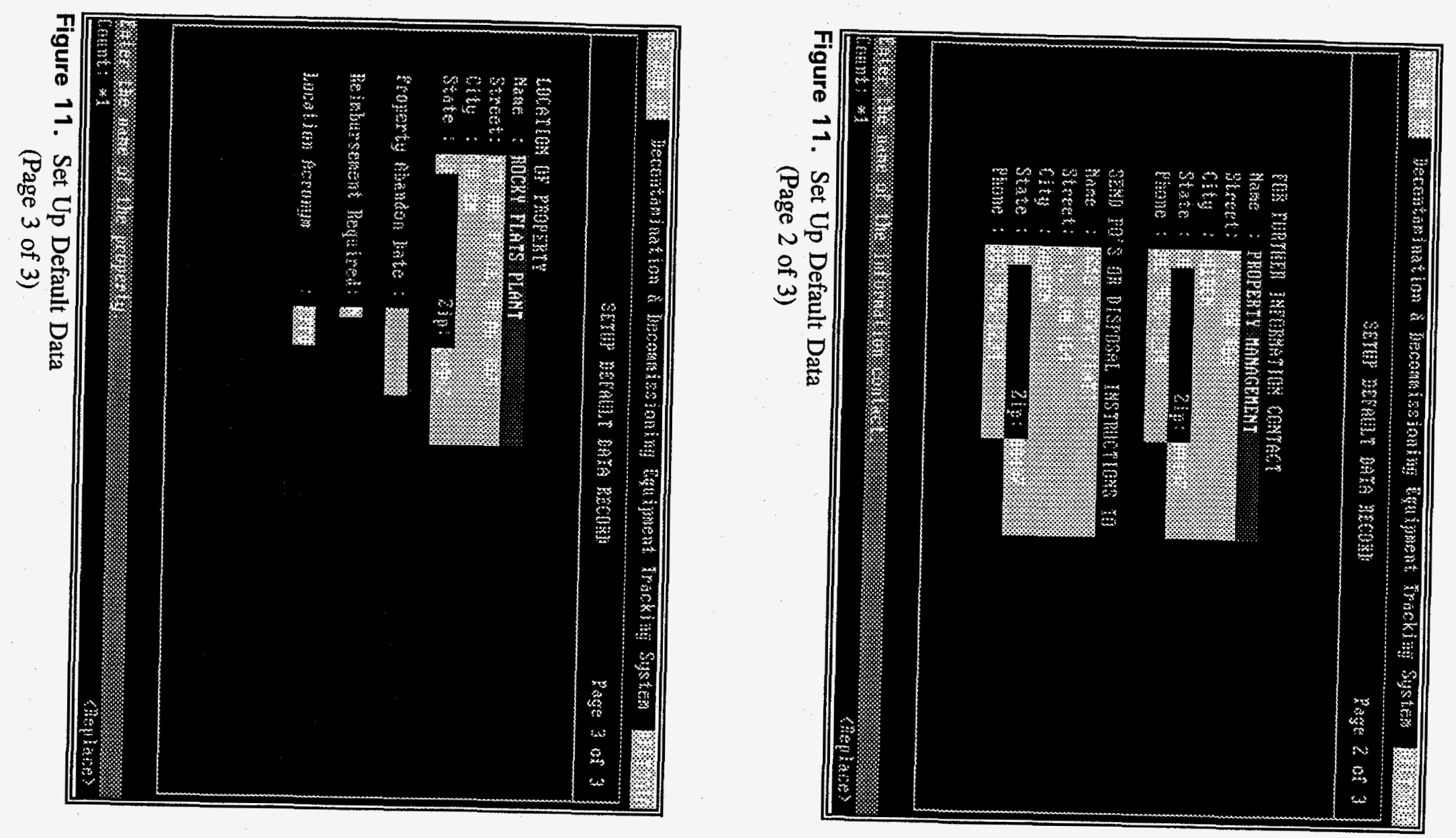


\subsection{Print Out Bar Code Labels}

This option enables the user to print out a single bar code or multiple bar codes (Figure 12). The user can then place the bar codes onto the corresponding container. Scanning bar codes enables the user to upload information to the DDETS system and to populate the database without having to re-enter information manually.

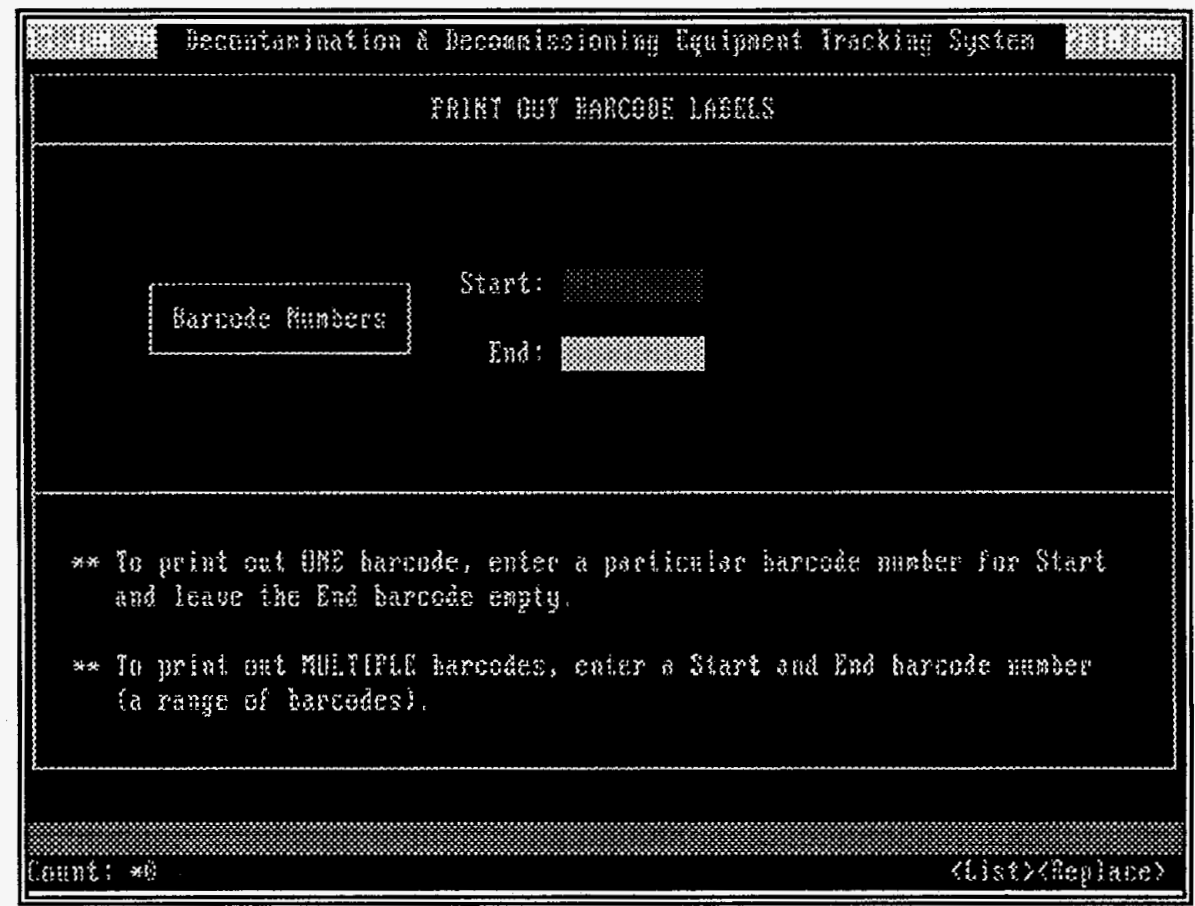

Figure 12. Print Out Bar Code Labels

By pressing F9, the system brings up a pop-up list of bar codes and equipment descriptions. The user can then highlight the appropriate item by use of the UP-ARROW or DOWN-ARROW key and pressing ENTER. The system automatically inserts the selected bar code into the field that was highlighted when the user invoked the F9 command (either the "Start" field or the "End" field). If the user wants to print bar codes for all equipment in the system, the bar code number field can be left blank when the user presses ENTER. 


\subsection{Upload Data}

This option enables the user to upload data collected from the bar code scanner to the DDETS database. The user collects (scans) the information in the field, returns to the office, hooks the scanner up to the PC, and selects UP LOAD DATA from the Utilities Main Menu. When the message "Communications OK. Ready to receive file..." appears on the screen, the user then selects the upload option on the scanner. Scanning bar codes enables the user to upload information and populate the database without having to re-enter equipment information manually.

\subsection{Data Back Up Utility}

This option enables the user to backup DDETS database information. The user can identify the backup destination (i.e., drive "A:", etc.)(Figure 13).

This utility only backs up DDETS data. A total system backup is not performed.

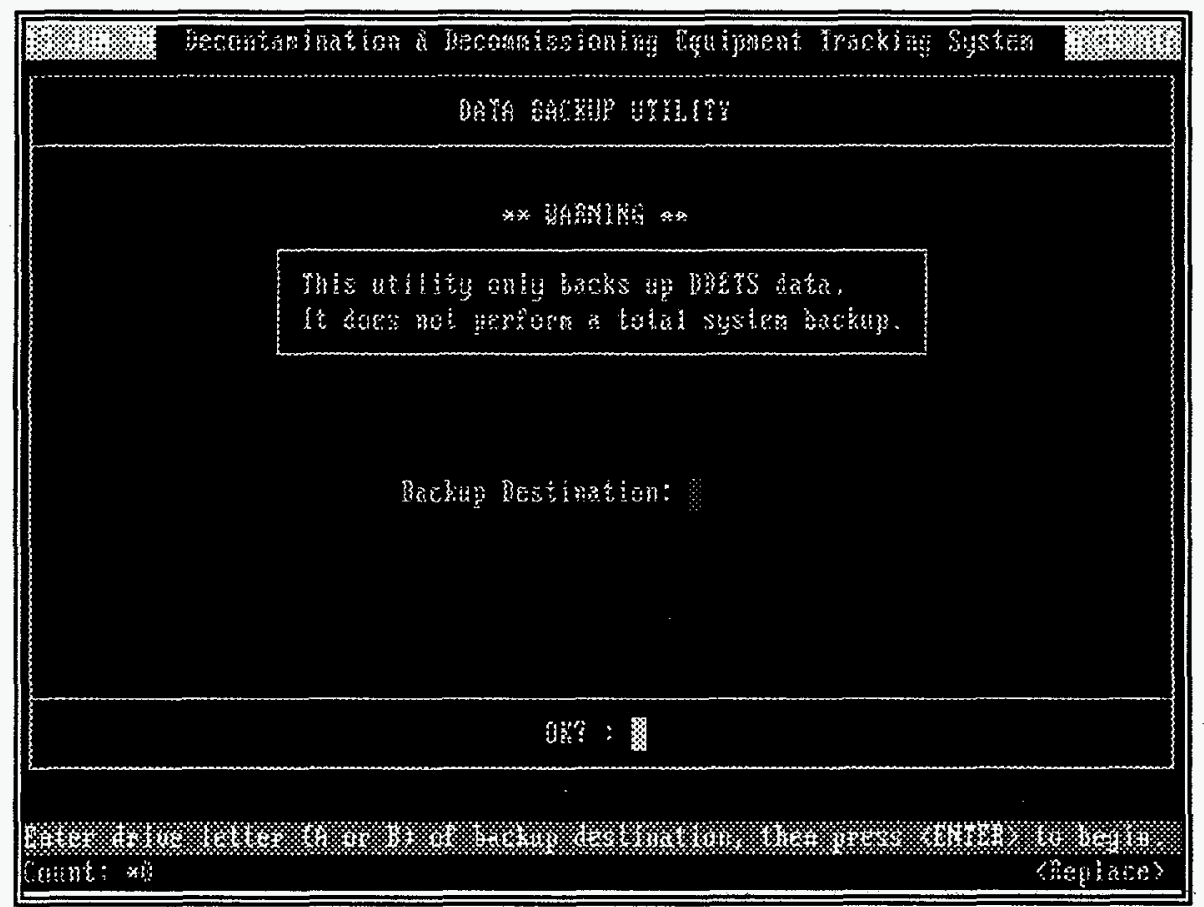

Figure 13. Back Up DDETS Data 